\title{
Wave Power Generation by Piezoelectric Sensor Attached to a Coastal Structure
}

\author{
Kyu-Han Kim $\mathbb{D},{ }^{1}$ Si-Bum Cho, ${ }^{2}$ Hyun-Dong Kim, ${ }^{3}$ and Kyu-Tae Shim $\mathbb{D}^{1}$ \\ ${ }^{1}$ Catholic Kwandong University, 579 Beon-gil, Gangneung, Gangwon-do, Republic of Korea \\ ${ }^{2}$ The Republic of Korea by National Disaster Management Research Institute, 365 Jongga-ro, Jung-gu, Ulsan, Republic of Korea \\ ${ }^{3}$ Osaka University, 565-0871, Suita, Osaka, Japan
}

Correspondence should be addressed to Kyu-Han Kim; khkim@cku.ac.kr

Received 14 September 2017; Accepted 1 February 2018; Published 8 April 2018

Academic Editor: Taesun You

Copyright ( 92018 Kyu-Han Kim et al. This is an open access article distributed under the Creative Commons Attribution License, which permits unrestricted use, distribution, and reproduction in any medium, provided the original work is properly cited.

The characteristics of a new wave power generating system have been proposed by installing a piezoelectric sensor to the seaward position of an existing coastal structure. By installing the sensor to the structure, waves will hit the piezoelectric sensor to generate wave energy; at the same time, the structure acts as a wave breaker. This technique can be applied to various coastal structures to converge the functions of renewable energy generator and the wave reducing structure. This technique of using piezoelectric sensor is relatively inexpensive that can be used for economic purposes as well. Throughout the study, usability of the existing coastal structure and characteristics of current research trend in the ocean wave energy retrieval of the wave power generators have been analyzed. Hydrographic analysis of this technique has been conducted by hydraulic model experiment using $2 \mathrm{D}$ wave flume and confirmed that the wave pressure and voltages maximize when higher wave with longer period of wave induces. Throughout the experiment, correlations of generation volume and wave conditions have been found.

\section{Introduction}

Carbon dioxide emissions from usage of fossil fuel are one of the major causes of global warming which cause problems in many aspects such as sea level rise, air pollution, and desertification. In particular, according to the IPCC (2014), it is predicted that in 2050 , the sea level will rise to about $0.2 \mathrm{~m}$ compared to the sea levels in 2010 [1]. Moreover, it is predicted that the island will gradually disappear and land area will be reduced. Under these circumstances, development of renewable energy has been studied diversely and diverse researches are in progress. This renewable energy is being produced in a variety of ways, including solar, wind, hydropower, and hydrogen gas; however, the performance has yet to reach a satisfactory level.

Because the oceans cover more than 70 percent of the earth, wave energy is expected to play an important role in the power supply plan due to the possibility of solving the energy problem in the future. There have been many attempts to use power generation facilities using this wave energy from all over the world. As showed in Figure 1, researchers studied a device that floats a generator on the surface of the ocean and drives the generator by wave motion, in Europe. In Australia, power generation equipment is applied by the vertical movement of waves in the water. In Korea, there is a power generation facility that generates electricity by rotating the turbine by pushing the air to the generator by a wave [2] and tries to find optimal shapes to increase wave energy [3]. But conventional wave devices have limited power generation areas and are unable to continuously produce stable electricity. As a result, the electric power generation efficiency was low, resulting in poor economic efficiency and practicality. To overcome these problems, this study proposed using piezoelectric sensor to generate the wave power energy.

A piezoelectric sensor is a sensor that generates a mechanical strain when an external force is applied or a deformation occurs when a voltage is applied to the sensor. The piezoelectric sensor is applied in various purposes in many industries and used widely such as medical industries, automobile industries, and information communication 


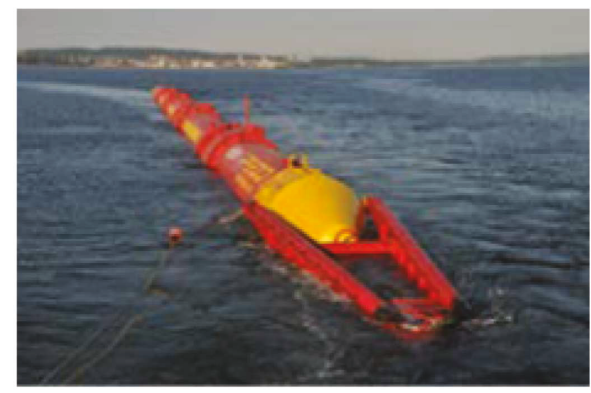

(a)

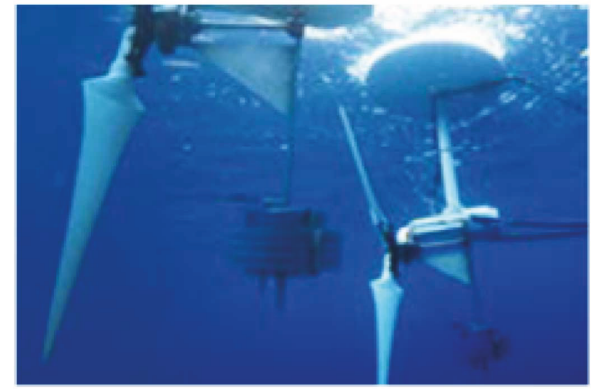

(c)

FIgure 1: Example of wave energy generation systems: (a) Pelamis, (b) CETO, (c) Sea horse, and (d) TidGen.

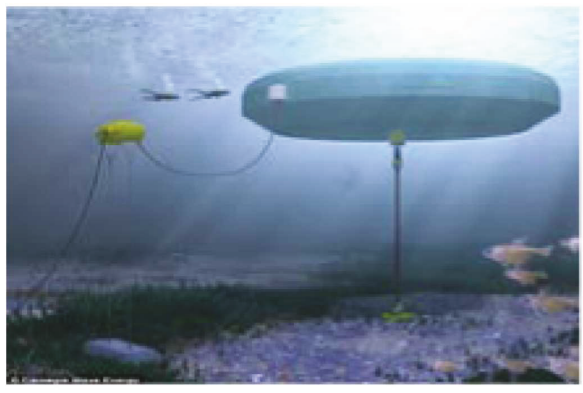

(b)

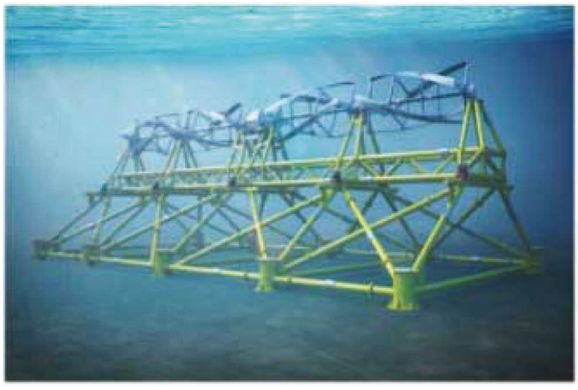

(d) industry. This piezoelectric sensor determines the energy level from the external force condition, and it is expected to collect high energy in the ocean where the main external force is expected to be collected. In particular, the coastal structure protects the harbor facilities from the high waves.

The wave is usually about 1 to $2 \mathrm{~m}$ in range; however, when the high swell induces, it increases up to $5 \mathrm{~m}$. Thus, to convert such wave energy into electric energy, this study proposes a new wave power generation system which derives the wave energy by the pressure applied to the front part by attaching the piezoelectric sensor device to the outside of the existing coastal structure. When the irregular waves impact the piezoelectric panel, the change of pressure caused by the wave power is outputted as the voltage through the measuring meter and converted into the amount of energy, and the maximum amount of generated energy is predicted by the power generation time.

In order to facilitate the construction and application in the field, it is possible to add the wave generation functions to the function of the original structure when applied to various coastal structures. Moreover, it is judged that this sensor can be applied to large-sized structure since it is possible to install large numbers of generators at relatively low cost by using unimorph piezoelectric sensor which is easy to handle. This new method will be analyzed by using both $2 \mathrm{D}$ hydraulic model test and numerical simulations.

\section{Piezoelectric Energy Harvesting System}

2.1. Element of Piezoelectric Sensor. Piezoelectric energy is a technology which converts mechanical energy into electrical energy. When an external force is applied to the piezoelectric system, electric charge is generated by drawing the charge generator in the system $[4,5]$. Using this principle, it is being applied in various fields such as ecofriendly energy like sun, wind, wave, and vibration. The unimorph piezoelectric device applied to this experiment has a circular thin piezoelectric ceramic plate attached on the metal diaphragm, although there are various types of piezoelectric devices with various applications.

The piezoelectric sensor can convert the mechanical energy and the electric energy from the functional aspect, and it is possible to directly apply the unimorph piezoelectric body to the power generation device for energy harvest; however, since energy efficiency is low, attempting to apply it to the electricity generation was low [6]. Nonetheless, this study investigates the generated energy due to the external force change through the fabrication of the power panel with high-energy element and the coupling of multiple devices. Conversion efficiency using the unimorph piezoelectric in Figure 2 shows a disc-shaped unimorph-type sensor with circular ceramic PZT attached on the side of the brass plate. This unimorph-type sensor generates electric output by the piezoelectric effect of ceramics using external vibration energy. Table 1 shows the specifications of the piezoelectric elements applied to the experiment.

\subsection{Piezoelectric Energy Harvesting System. Energy harvest-} ing refers to the technique of harvesting unused energy around us, such as light, temperature difference, and vibration energy, into useful electric energy [7]. The piezoelectric energy collection system applied to this study was designed to examine the energy generation efficiency and applicability to coastal structures in areas with wide wave energy width. It also includes the characteristics of wave power generation system in which the pressure is transmitted to the center of 

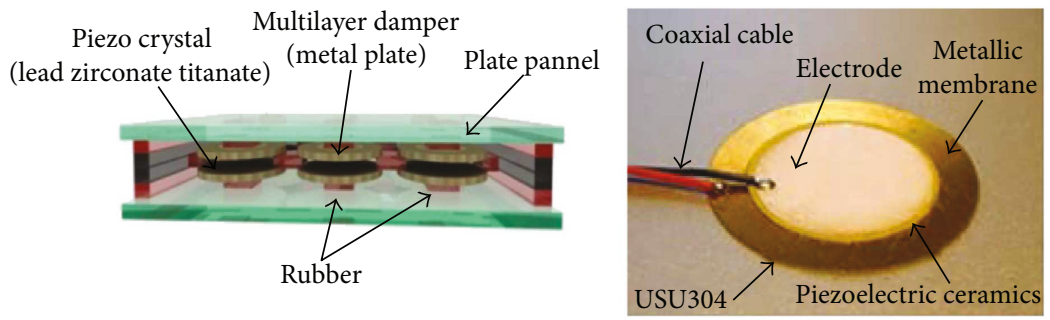

FIgURe 2: Piezoelectric element.

Table 1: Piezo element specifications.

\begin{tabular}{lc}
\hline Items & Value \\
\hline Resonant frequency & $15.0 \pm 1.0 \mathrm{KHz}$ \\
(Fr) & $9000 \pm 30 \% \mathrm{pF}$ at $1000 \mathrm{~Hz} / 1 \mathrm{~V}$ \\
Main electrostatic capacity & $500 \Omega \mathrm{max}$ \\
Resonant impedance & $\mathrm{SUS} 304$ \\
Metal plate material & $12.0 \pm 0.10 \mathrm{~mm}$ \\
Metal plate diameter & $0.20 \pm 0.02 \mathrm{~mm}$ \\
Metal plate thickness & $9.0 \pm 0.20 \mathrm{~mm}$ \\
Ceramic diameter & $0.32 \pm 0.05 \mathrm{~mm}$ \\
Total height & $100 \mathrm{M} \Omega \mathrm{min}$ \\
Insulation resistance & $30 \mathrm{Vp}-\mathrm{p}$ \\
Maximum input voltage & $-20^{\circ} \mathrm{C} \mathrm{to}+70^{\circ} \mathrm{C}$ \\
Operating temperature range & \\
\hline
\end{tabular}

the system to generate a voltage when the main external force wave is applied to the device.

As shown in Figure 2, in order to increase the efficiency of the energy harvesting, multiple piezoelectric sensor devices are installed to facilitate the generation of electric power, and the energy transfer to the external force generation can be continuously operated. In addition, a total of 72 devices were attached to six panels by dividing each panel into 6 pieces, and elastic rubber was attached to the device to prevent damage of the piezoelectric sensor device due to external force.

Since the piezoelectric effect generated by the MLCC (multilayer ceramic capacitor) differs from that of the widely used polarized PZT, it is necessary to carefully examine what results are obtained depending on the state of the input signal and the MLCC [8]. However, in this study, since unimorphtype PZT is installed in duplicate, energy collection and trend analysis are easier. As the coastal structures used in the experiment, caisson-type breakwater was applied to perform the normal function of the port facility since it effectively reduces the high waves in deep water depth. Particularly, it is possible to produce energy by wave by attaching the device to the upper part of the front side of the breakwater where high wave, the main external force, intensively influences. Figure 3 shows a device and a panel attached to the structure.

\section{Physical Model Test}

3.1. Setting of Experiment Conditions. Two-dimensional cross-sectional hydraulic model experiments were conducted

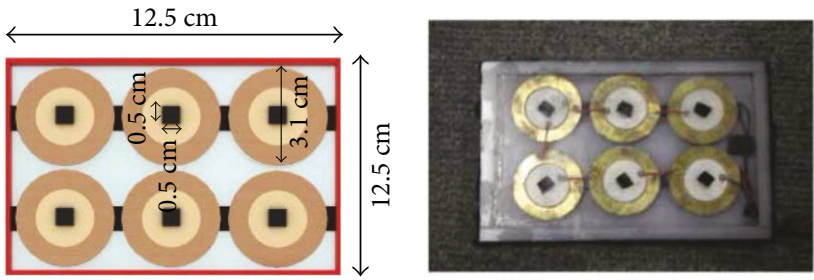

FIgURe 3: Piezoelectric energy harvesting system.

through wave flume (W: $1.0 \mathrm{~m} \times \mathrm{L}: 40 \mathrm{~m} \times \mathrm{H}$ : $1.5 \mathrm{~m}$ ) and generated both irregular and regular waves by the frequency of spectrum function (Figure 4). The water surface is made of tempered glass, and it is designed to observe not only the experimental section but also the general tendency of the incident waves. It can minimize the amplification and decrease of the set wave height during the experiment because the absorption wave system is embedded as shown in Figure 4.

Experiments were conducted to evaluate the power generation characteristics of the piezoelectric sensor devices due to the wave action after attaching them to the front part by installing the caisson breakwater specially manufactured in the wave flume. In addition, when the wave gauges are used to examine the magnitude of the wave, the magnitude of the voltage generated at the same time and the change in wave height at the front of the structure were measured. The filtration system applied to the air defense system has no change of steam, the vibration of the air is equipped with the detector, and the external force is measurable. Table 2 shows the specifications of wave pressure meter.

To measure the incident wave height, wave gauges are installed at the front of the caisson. The experimental wave height and the period analysis were analyzed by zero up crossing method using 8192 data after the standing waves were generated. The measured data were stored at $20 \mathrm{~Hz}$ intervals, and the measured values measured at the peak and the wave meter and voltages throughout the oscilloscope were subjected to a postanalysis using calibration coefficients recoded before the experiment. The experiment was repeated three times under the same conditions. Figure 5 shows the measurement equipment.

The external force which is the most important factor in the experiment was set to 21 experiments including seven peaks and three cycles corresponding to the normal wave, and the ideal wave conditions which are generally invaded in Korea and energy production from waves were 


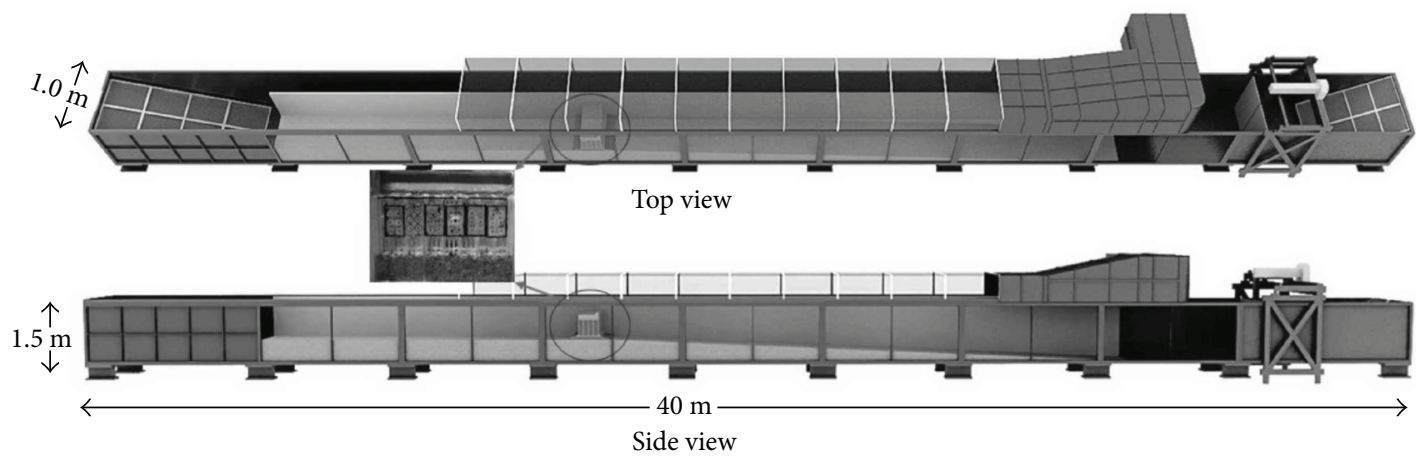

Figure 4: 2D wave flume.

TABLE 2: Spec. of wave pressure meter.

\begin{tabular}{|c|c|}
\hline Items & Value \\
\hline Sensor model & PS-05KC \\
\hline Rated capacity & $50 \mathrm{kPa}$ \\
\hline Rated output & $0.25 \mathrm{mV} / \mathrm{V}(500 \mu \mathrm{m} / \mathrm{m})$ \\
\hline Temperature effect on output & Within $\pm 0.3 \% \mathrm{RO} /{ }^{\circ} \mathrm{C}$ \\
\hline Natural frequency (appr.) & $10 \mathrm{kHz}$ \\
\hline Nonlinearity \& hysteresis & Within $\pm 1 \%$ RO \\
\hline Safe overload rating & $150 \%$ \\
\hline Safe excitation voltage & $3 \mathrm{~V}, \mathrm{AC}$ or $\mathrm{DC}$ \\
\hline Input \& output resistance & $350 \Omega \pm 10 \%$ \\
\hline 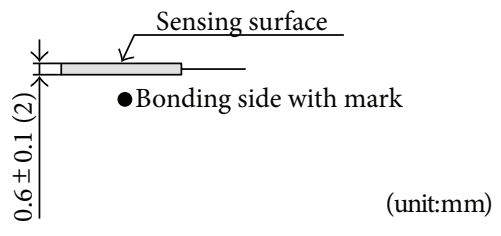 & \\
\hline
\end{tabular}

examined in each condition. Froude ratio was applied to be $1 / 40$ throughout the experiment and each condition is listed in Table 3.

3.2. Test Result. The voltage generated from the piezoelectric energy harvesting system was examined by using a wide range of wave energy, and the irregular waves with a tendency to be apparent were summarized. Experiments conducted are basic studies to evaluate the efficiency of generated energy when applied to an actual coastal structure, and they are different from those using existing turbines.

As Figures 6 and 7 listed experimental results in 21 different conditions, the intensity acting on the member varies according to the wave energy and the energy generation also changes proportionally. The results are analyzed by time series data and summarized for maximum generated wave pressure and corresponded to maximum generated voltages. As shown in Table 3, when the period increased, the intensity of wave pressure and voltage is proportionally increased. In other words, it was found that the generated energy was

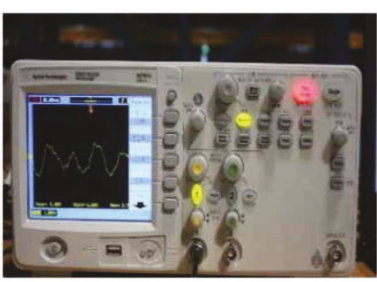

(a)

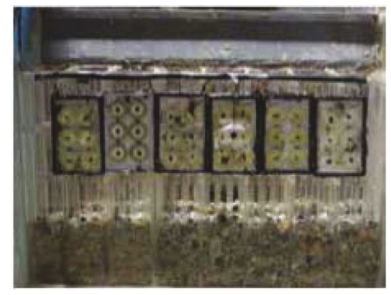

(c)

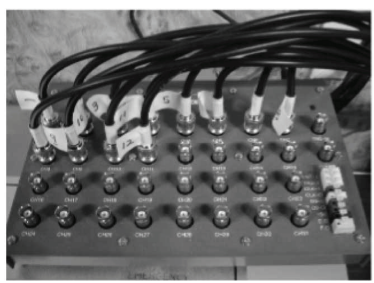

(b)

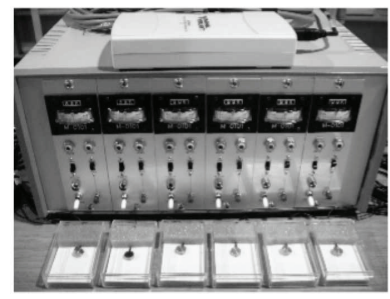

(d)
FIgURE 5: Experimental systems: (a) oscilloscope, (b) A/D convertor, (c) generation system, and (d) wave pressure meter and amplifier.

TABLE 3: Experimental conditions.

\begin{tabular}{lcccc}
\hline Case & Water depth $(\mathrm{cm})$ & Hs $(\mathrm{cm})$ & Tp $(\mathrm{sec})$ & H/Lo \\
\hline $\begin{array}{l}\text { Case } \\
01-21\end{array}$ & 50 & $1.25 \sim 12.5$ & $0.50 \sim 1.66$ & $0.013 \sim 0.071$ \\
\hline
\end{tabular}

proportional to the intensity of the external force, and it was formed in the range of 2.30 to $7.75 \mathrm{kPa}$ and 3.55 to $11.24 \mathrm{~V}$ for bolt values. Moreover, analysis of generated external force and voltage revealed that about $12.35 \mathrm{~mW}$ was generated in case 21 , which is the condition wave pressure, and the bolt values are maximum.

\section{Numerical Modeling}

4.1. CADMAS-SURF. Numerical wave channel was used for the numerical simulation which is to numerically investigate the characteristics of the external forces acting on the coastal structures. This model is based on the continuity equation and the kinetic equation for two-dimensional incompressible viscous fluid, and the following basic equation is extended to the porous model [9] as a basic equation. 


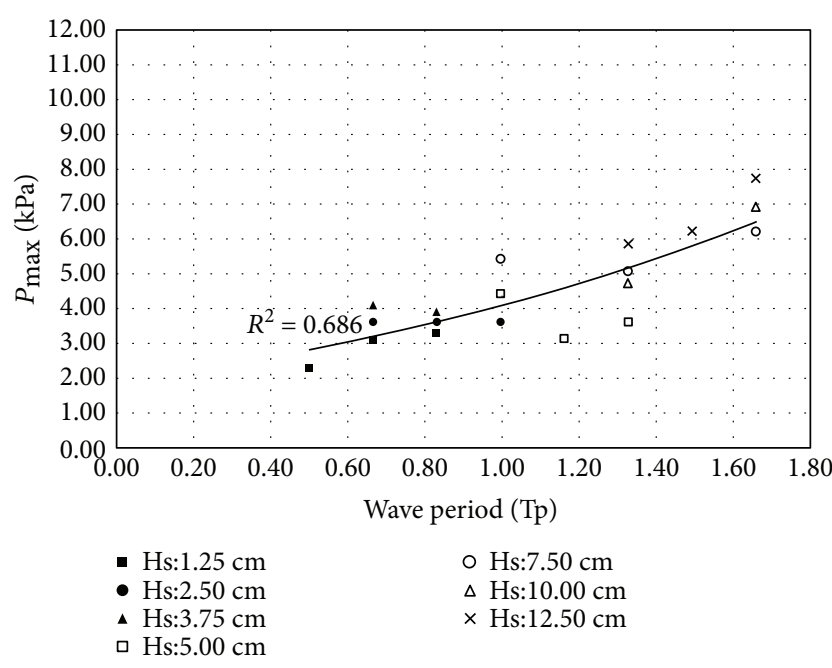

(a)

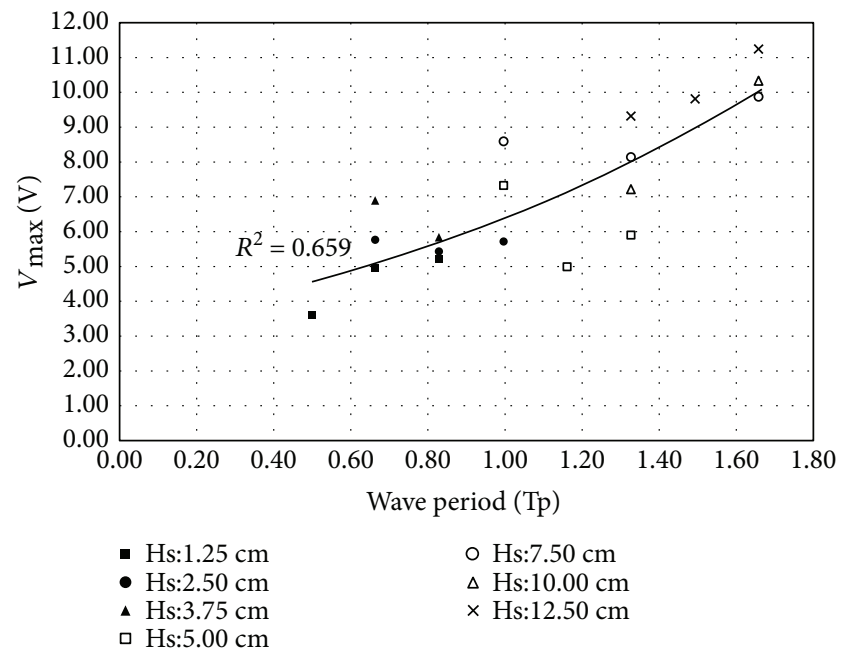

(b)

Figure 6: Comparison of wave period (Tp) and maximum wave pressure (a) and voltage (b).

Continuity equation

$$
\frac{\partial \gamma_{x} u}{\partial x}+\frac{\partial \gamma_{x} w}{\partial x}=S
$$

Dynamic equation

$$
\begin{aligned}
\lambda_{v} \frac{\partial u}{\partial t}+\frac{\partial \lambda_{x} u u}{\partial x}+\frac{\partial \lambda_{z} w u}{\partial z}= & -\frac{\gamma_{v}}{\rho} \frac{\partial p}{\partial x}+\frac{\partial}{\partial t}\left(\gamma_{x} v \tau_{x x}\right) \\
& +\frac{\partial}{\partial z}\left(\gamma_{z} v \tau_{x z}\right)-D_{x} u \\
& +S-R_{x}, \\
\lambda_{v} \frac{\partial w}{\partial t}+\frac{\partial \lambda_{x} u w}{\partial x}+\frac{\partial \lambda_{z} w w}{\partial z}= & \frac{\partial}{\partial x}\left(\gamma_{x} v \tau_{z x}\right)-\frac{\gamma_{v}}{\rho} \frac{\partial p}{\partial z} \\
& +\frac{\partial}{\partial z}\left(\gamma_{z} v \tau_{z z}\right)-D_{z} w \\
& +S-R_{x}-\gamma_{v} g .
\end{aligned}
$$

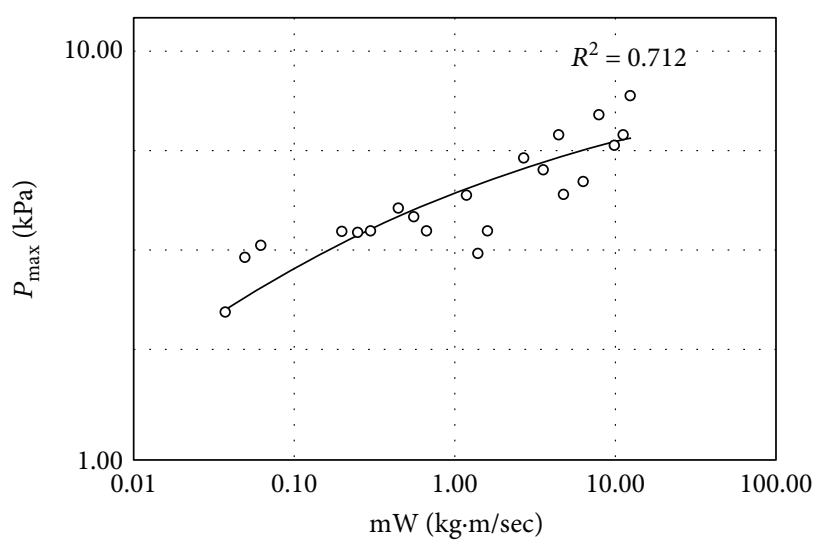

(a)

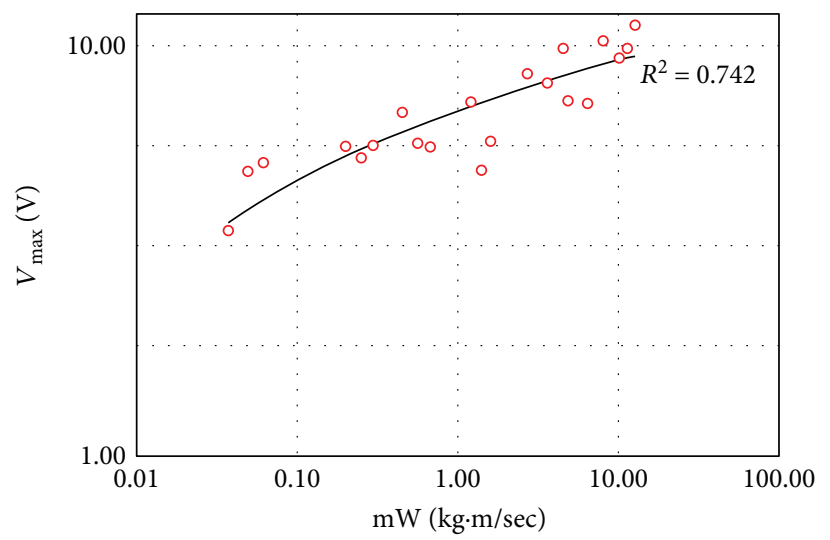

(b)

FIgURE 7: Comparison of watt $(\mathrm{mW})$ and maximum wave pressure (a) and voltage (b).

TABle 4: Computational conditions.

\begin{tabular}{lcccc}
\hline Case & Grid resolution & Wave type & Duration & H/Lo \\
\hline Case & $\triangle x \times \triangle z=1 \times 1 \mathrm{~cm}$ & $\begin{array}{c}\text { Irregular } \\
\text { wave }\end{array}$ & $440 \mathrm{sec}$ & $0.013 \sim 0.032$ \\
$01-21$ & & & & \\
\hline
\end{tabular}

Here, $t$ is time, $x$ and $y$ are horizontal and vertical coordinates, and $u$ and $v$ are velocity components in the horizontal and vertical directions in (1). From (2) and (3), density $\rho$, pressure $p$, tensile coefficient $v$, gravitational acceleration $g$, volumetric porosity $\gamma_{v}$, and horizontal and vertical area porosity $\gamma_{x}$ and $\gamma_{z}$ were used. Deformation velocity tensor $\boldsymbol{\tau}_{\mathrm{ij}}$, reflection attenuation coefficient at boundary attenuation $D_{\mathrm{x}}$ and $D_{\mathrm{z}}$, a code term for wave in the sea zone $S$, and a resistance permeability $R_{x}$ and $R_{z}$ are used, and $\lambda_{v}, \lambda_{x}$, and $\lambda_{z}$ are calculated as following:

$$
\begin{aligned}
& \lambda_{v}=\gamma_{v}+\left(1-\gamma_{v}\right) C_{M}, \\
& \lambda_{x}=\gamma_{x}+\left(1-\gamma_{x}\right) C_{M}, \\
& \lambda_{z}=\gamma_{z}+\left(1-\gamma_{z}\right) C_{M} .
\end{aligned}
$$

Here, $C_{M}$ is the inertia force coefficient. In addition, the VOF method is used for the analysis of the water surface, 


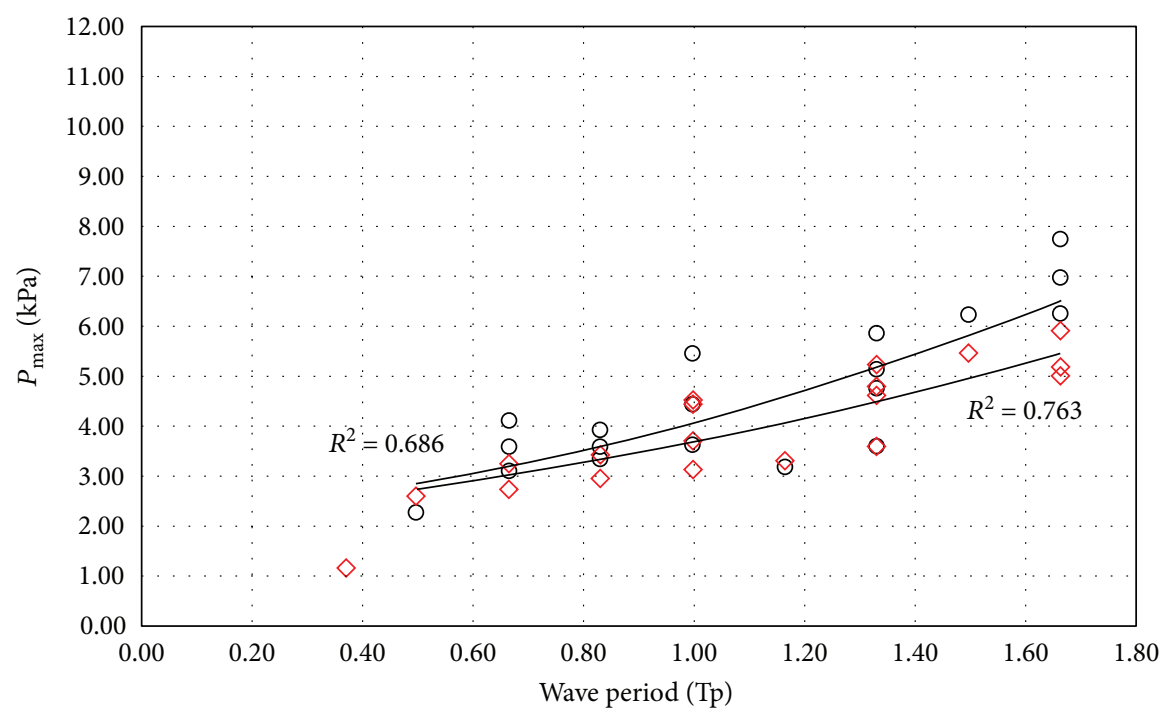

O Physical model test

$\diamond$ Numerical wave channel

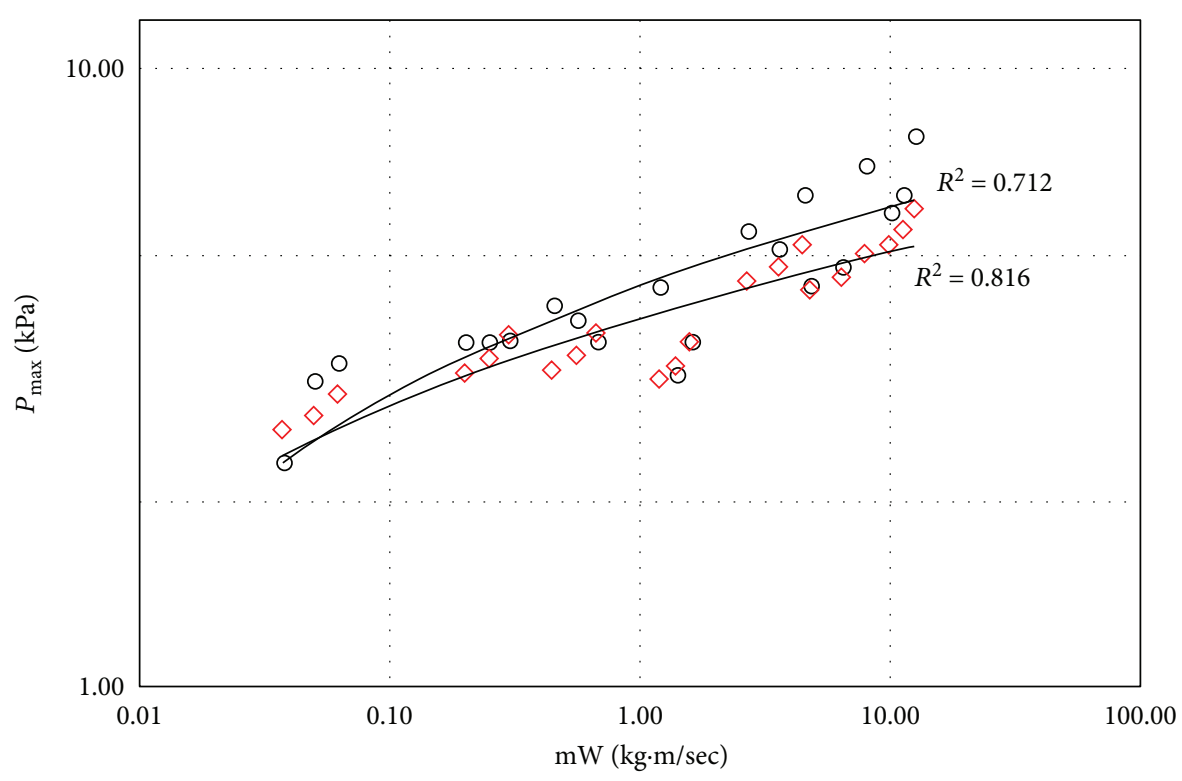

O Physical model test

$\diamond$ Numerical wave channel

FIGURE 8: Comparison result with numerical and physical model test.

which is highly versatile and can be applied to complex free-surface shape.

4.2. Calculation Condition. The computational domain was performed under the same conditions as the hydraulic model experiment, and impervious boundary conditions were applied to both sides and bottom of the computational domain. Experiments were carried out to examine the changes in wave pressure against the wet wave. Table 4 summarizes the calculation conditions.

4.3. Modeling Result and Analysis. As shown in Figure 8, the relationship among wave period, generated electric power, and maximum wave pressure is presented. The numerical results are also compared with physical model tests for the review in overall tendency. In case of wave pressure, both results showed a tendency to increase as the period and power increased; however, the result is steeper in the physical model test. This phenomenon is because of the breaking wave pressure acting on the structure when wave is broken right in front of the structure. Therefore, it was found that the maximum wave pressure is generated with breaking wave pressure, and for gathering high efficiency of electric power, the condition for occurrence of breaking wave pressure is more terms that are advantageous. 
Throughout the experiment results, increase of wave energy is proportional to wave pressure and voltage generation, and it is possible to estimate the amount of power generation through various experiments.

\section{Conclusion}

In this study, the efficiency and power of the generated energy were investigated by measuring the wave pressure and voltage according to the wave activity using the piezoelectric element and the harvesting system which are mechanical energy conversion devices. Piezoelectric sensor devices are characterized by the momentary energy generation due to external force changes, and irregular waves are suitable for application to coastal structures which continuously invade.

As a result, the wave pressure and voltage were increased with increasing wave energy, and it was confirmed that maximum $7.75 \mathrm{kPa}$ and $11.24 \mathrm{~V}$ were calculated within experimental conditions. Under these conditions, the generated power is about $12.35 \mathrm{~mW}$, and when applied to the actual sea area, the amount is increased by the super compact rule, and it is considered to play an important role as a substitute resource of the compost fuel.

In the future, we will examine ways to maximize the energy efficiency and review and propose the optimal shape and maximum power generation efficiency of the piezoelectric energy collecting device for application to the actual sea area.

\section{Conflicts of Interest}

The authors declare that they have no conflicts of interest.

\section{References}

[1] IPCC, Climate Change 2014: Synthesis Report. Contribution of Working Groups I, II and III to the Fifth Assessment Report of the Intergovernmental Panel on Climate Change, Core Writing Team, R. K. Pachauri, and L. A. Meyer, Eds., IPCC, Geneva, Switzerland, 2014.

[2] K. H. Kim and J. Cahyono, "Numerical study on impeller performance of mini hydro turbine," Applied Mechanics and Materials, vol. 772, pp. 552-555, 2015.

[3] S. Shin, K.-H. Lee, D.-S. Kim, K.-H. Kim, and K. Hon, "A study on the optimal shape of wave energy conversion system using an oscillating water column," Journal of Coastal Research, vol. 165, pp. 1663-1668, 2013.

[4] M. Kim, "Mechanical vibration energy harvesting," Journal of the Korean Society for Nondestructive Testing, vol. 32, no. 5, pp. 603-610, 2012.

[5] Y.-H. Kim, "A study of output characteristics for the generation panel using unimorph piezoelectric element," Journal of the Korean Institute of Electrical and Electronic Material Engineers, vol. 23, no. 3, pp. 250-259, 2010.

[6] C. Keawboonchuay, "Maximum power generation in a piezoelectric pulse generator," IEEE Transactions on Plasma Science, vol. 31, no. 1, pp. 123-128, 2003.

[7] C. Keawboonchuay and T. G. Engel, "Electrical power generation characteristics of piezoelectric generator under quasi-static and dynamic stress conditions," IEEE Transactions on Ultrasonics, Ferroelectrics and Frequency Control, vol. 50, no. 10, pp. 1377-1382, 2003.

[8] N.-C. Park, B.-H. Ko, Y.-P. Park, and Y. Ahn, "Study on behavior of multilayer ceramic capacitor caused by piezoelectricity," Transactions of the Society of Information Storage Systems, vol. 10, no. 2, pp. 61-64, 2014.

[9] T. Sakakiyama and R. Kajima, "Numerical simulation of nonlinear wave interacting with permeable breakwaters," in Coastal Engineering 1992, Venice, Italy, October 1992. 


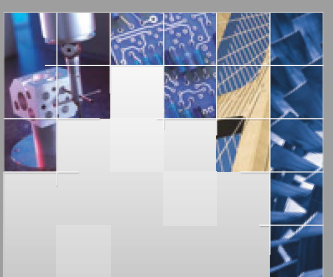

\section{Enfincering}
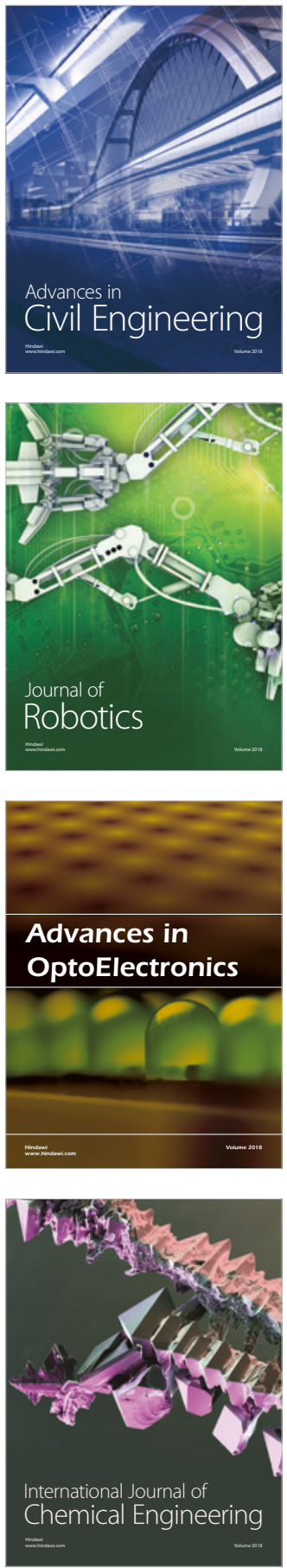

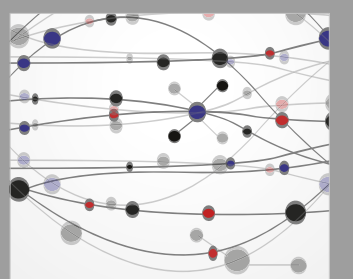

\section{Rotating \\ Machinery}

The Scientific World Journal

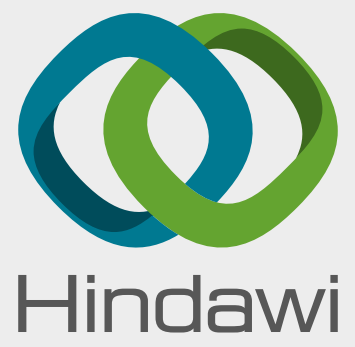

Submit your manuscripts at

www.hindawi.com
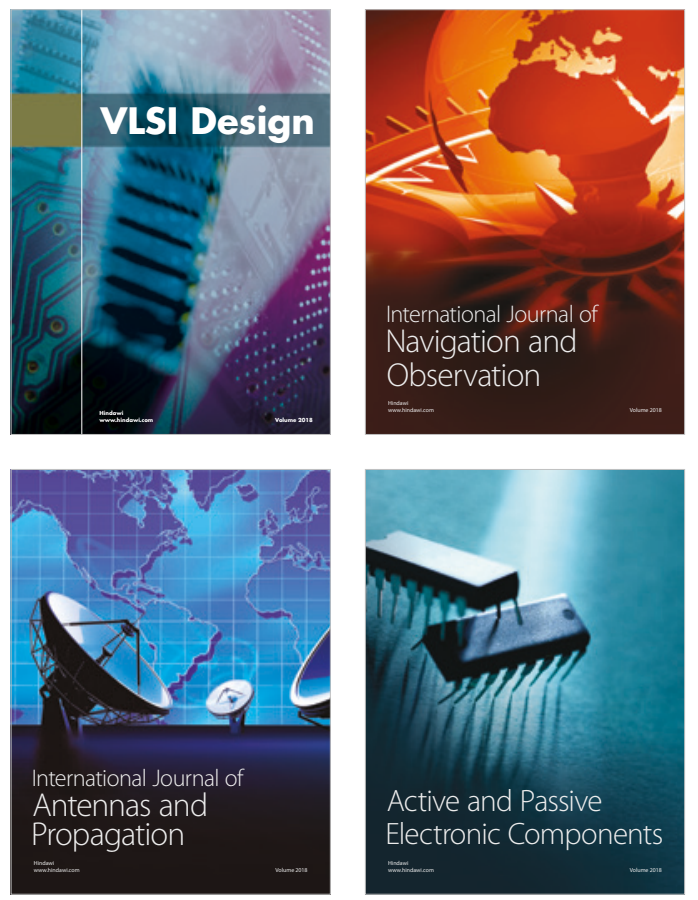
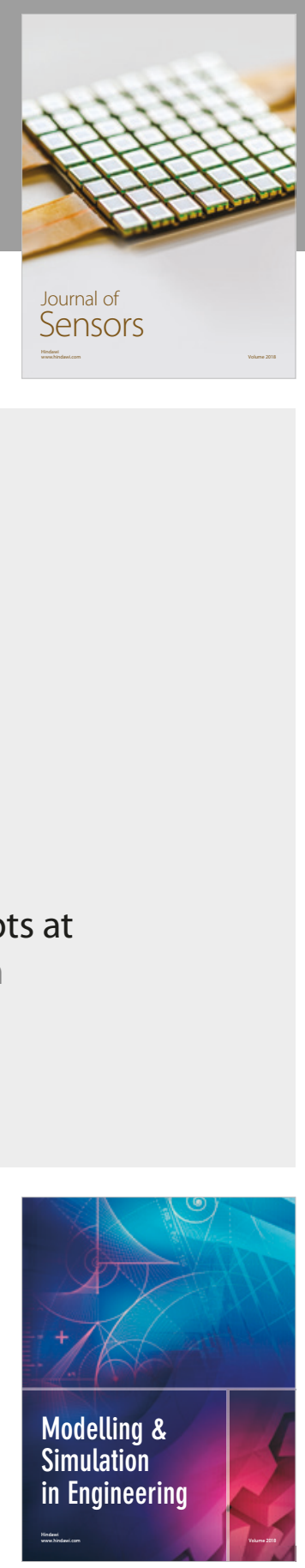

\section{Advances \\ Multimedia}
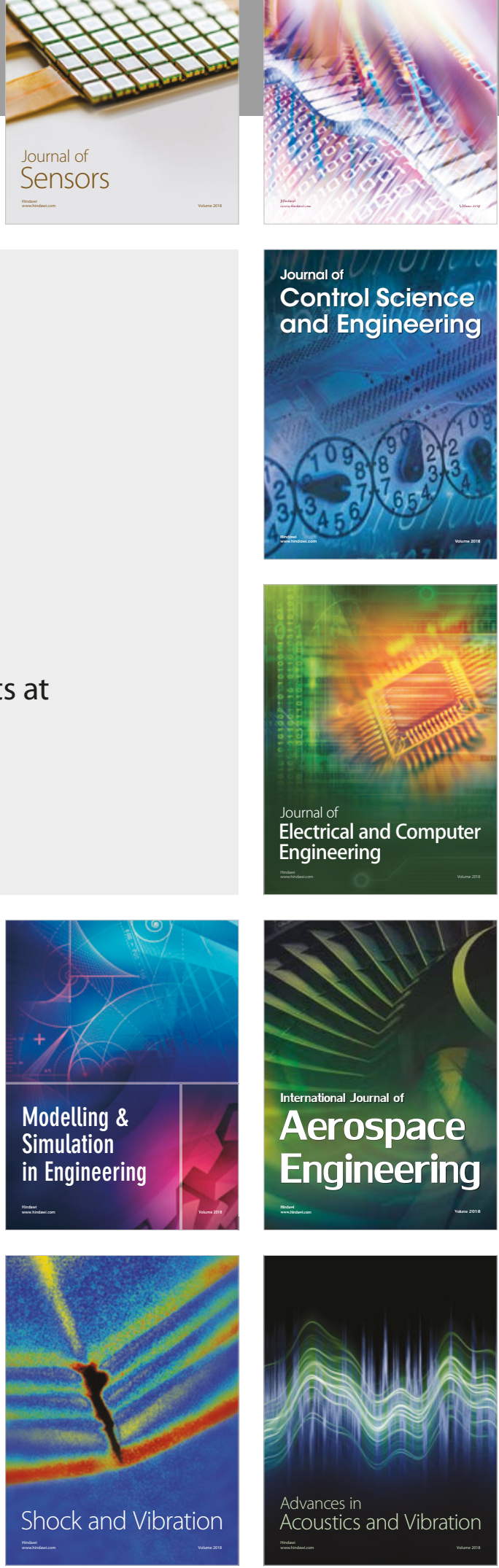